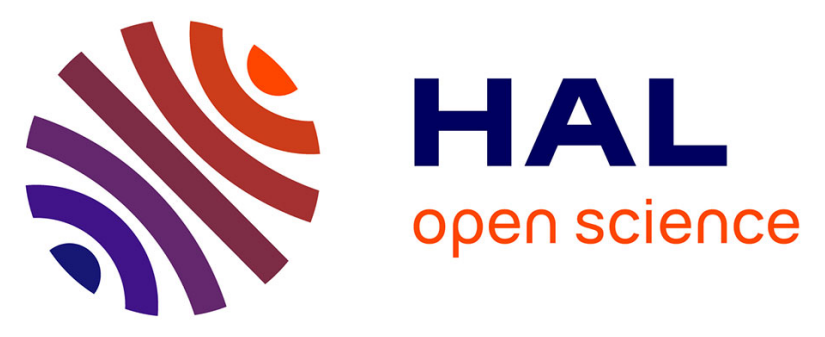

\title{
Weather Data Handlings for Tornado Recognition Using mHGN
}

\author{
Benny Benyamin Nasution, Rahmat Widia Sembiring, Muhammad \\ Syahruddin, Nursiah Mustari, Abdul Rahman Dalimunthe, Nisfan Bahri, \\ Bertha Br Ginting, Zulkifli Lubis
}

\section{To cite this version:}

Benny Benyamin Nasution, Rahmat Widia Sembiring, Muhammad Syahruddin, Nursiah Mustari, Abdul Rahman Dalimunthe, et al.. Weather Data Handlings for Tornado Recognition Using mHGN. 2nd International Conference on Information Technology in Disaster Risk Reduction (ITDRR), Oct 2017, Sofia, Bulgaria. pp.36-54, 10.1007/978-3-030-18293-9_5 . hal-02280323

\section{HAL Id: hal-02280323 \\ https://hal.inria.fr/hal-02280323}

Submitted on 6 Sep 2019

HAL is a multi-disciplinary open access archive for the deposit and dissemination of scientific research documents, whether they are published or not. The documents may come from teaching and research institutions in France or abroad, or from public or private research centers.
L'archive ouverte pluridisciplinaire HAL, est destinée au dépôt et à la diffusion de documents scientifiques de niveau recherche, publiés ou non, émanant des établissements d'enseignement et de recherche français ou étrangers, des laboratoires publics ou privés. 


\title{
Weather Data Handlings for Tornado Recognition using mHGN
}

\author{
Benny Benyamin Nasution, Rahmat Widia Sembiring, Muhammad Syahruddin, \\ Nursiah Mustari, Abdul Rahman Dalimunthe, Nisfan Bahri, \\ Bertha br Ginting, Zulkifli Lubis \\ Politeknik Negeri Medan, Indonesia, \\ Jalan Almamater No. 1, Kampus USU, Medan 20155, Indonesia \\ benny.nasution@polmed.ac.id
}

\begin{abstract}
The usage of the $\mathrm{mHGN}$ as a pattern recognizer cannot necessarily be used to recognize tornados. Two important issues that need to be solved first are related to data handlings of not-accurately recorded data, and to those of complex weather data. The not-so-appropriate data handlings will produce high false positive and true negative rate of the recognition results. Yet, the latest development of those data handlings has been carried out, and has shown positive and promising results. Such a new approach of data handlings can, therefore, be used to improve the quality and the accuracy of forecasting a tornado. The results taken from a simulated circumstances of a multidimensional pattern recognition have shown, that the tornado can be recognized around 9 hours earlier with $90 \%$ of accuracy. However, several improvements related to the data representation within the mHGN architecture need to be implemented. The deployment of mHGN in several risky areas of tornados can then be expected as an alternative way of reducing damages, losses, and costs.
\end{abstract}

Keywords: Graph Neuron, Hierarchical Graph Neuron, Multidimensional Hierarchical Graph Neuron, Natural Disaster Forecast, Tornado Forecast

\section{Introduction}

The latest storms that hit several countries across the gulf part of American continent have given a clear evidence that natural disasters are real, and they will occur regularly. Although the upcoming of a storm can be monitored and people are usually notified many hours before it arrives, damages, injures, and casualties are usually still involved. The reason to this is maybe because not only the upcoming is important, but also the lack of preparation of people contributes to those damages and casualties. The clear evidence to this is the two tsunamis: in Indonesia in 2004, and in Japan in 2011. The situation is worse when the disaster is a tornado, because it occurs without an adequate notification (siren, alarm, or radio announcement). In the US [1] [2] the number of occurrences of a tornado is the highest compared to those in other countries. 
The reason why the occurrence of natural disasters cannot be forecasted is due to its randomness. Furthermore, many people are not aware of the precondition of its occurrence, and they are not prepared to face that. Such a randomness is not the case of a tornado. In the US, tornados are not random. Most of tornados occurred between April and June. The area of occurrences is in the southeast area of the US. Nevertheless, every single tornado appears very suddenly. Prior to its appearance there is no sign that can be recognized beforehand, for instance at least 10 hours earlier, so that people have adequate time to get away of it. As the result, damages, losses, and costs totally cannot be predicted.

Researchers have worked on handling natural disasters. The general term that they have developed is called disaster management. The management deals with prior, while, and post disaster. The most difficult part dealing with natural disaster, such as a tornado, is to forecast it. It is true that some kind of early warning system has been built in many countries. In the US, a siren is started when the system detects an upcoming of a tornado. However, the time distance between the siren and the occurrence of tornado is very short. It is usually less than 30 minutes. Such period of time is inadequate for people to protect themselves from the fierce of tornado's force. For centuries researchers have worked on discovering ways to forecast the upcoming of a natural disaster. Some of them are still at the stage of now-casting [3] [4] [5] [6] [7], not yet forecasting. Some believe that the most difficult part of forecasting natural disasters is producing the mathematical formulas of it [8].

So, it is a strong indication that other methods than mathematical formulas to forecast a tornado are required. A number of researchers [8] have developed an artificial intelligent technology to forecast an upcoming tornado. Although there is no definite mathematical functions that can be used to determine the condition of a tornado, windspeed, wind-direction, air-temperature, and air-pressure that constitute a tornado, are all caused by physical states [9]. It means that the time-series of several physical values of wind-speed, wind-direction, air-temperature, and air-pressure determine particular tornado condition. It can then be figured out that the upcoming of a tornado is generally produced by particular physical patterns.

The physical patterns that have been used in mHGN [8] were not yet ready for forecasting tornados, although $\mathrm{mHGN}$ is able to recognize incomplete alphabetical patterns [9]. There are two major issues why mHGN is not ready to forecast tornados. First, the physical values of weather data need to be represented using sophisticated scheme so, that false positive and true negative rates can be reduced significantly. Second, the occurrence of a tornado not at the location where the measuring sensors of weather for wind-speed, wind-direction, air-temperature, and air-pressure are located. Therefore, a sophisticated approached is required so that the patterns from previous occurrences of tornados can be used as the training pattern for future purposes.

In this paper, those two issues are elaborated in order to improve the accuracy of mHGN in forecasting tornados. 


\section{Tornado Recognition}

Natural disasters have become common issues in the world. United Nation's UNISDR has been the primary organization that works tightly with disasters around the world. Since natural disasters have occurred in many countries, people across the world are hand in hand helping each other in facing natural disasters. This situation has helped researchers in gaining data from sensors scattered in the world. Researchers have started since long time ago investigating new approaches in forecasting natural disasters. As many parameters and conditions need to be considered, many issues related to forecasting natural disasters need to be investigated further.

The possibility of the occurrence of a natural disaster varies, but it is still there in most parts of the world. For instance, the tsunami that hit Indonesia in 2004 had never been experienced by Indonesians for hundreds of years. This situation applies for other natural disasters. Some countries have experienced natural disasters more than others [8]. This situation has been the main reason why a country such as the US has spent a lot of efforts to deal with natural disasters. When the circumstances of a tornado to come up in an area have reached, it is very likely that the area will suffer from a tornado. Most tornados occurred in the US have caused damages, losses, and costs. However, this does not mean that only the US must concern with the occurrence of tornados.

The randomness of the occurrence of a natural disaster is not only in terms of the location, but also in terms of the time and the severity. However, the location and the time (season) of tornados to occur is generally the same. Previous tornados occur between April and June, and the most countries that have been hit are those in the southeast area of the US. Although many researchers in opinion that the severity and the average magnitude of natural disasters have increased since the last decade. However, it is still not clear how severe future natural disasters might be. The impossibility of measuring, or predicting the severity of natural disasters, has been the major cause of the difficulties in anticipating their occurrences. Many other researchers have suggested that, one way to deal with the randomness of the occurrence of natural disasters is through a disaster forecaster.

Early warning system [2] and now-casting [1] [10] [11] [5] [3] [6] that have been investigated and developed are not yet able to help people avoiding and mitigating natural disaster. If the time frame of detecting a tornado is short, people will not be able to save themselves away from the tornado. For instance, the forecasting approach that they [12] [7] [4] have attempted is able to forecast the disaster, but only within one hour time frame. Despite those efforts of researchers, Sorensen [2] argues that in terms of prediction and forecasting, still no radical breakthroughs have occurred in the past twenty years. Due to its complexities, most natural disaster researchers are working on technologies that are not focusing on the forecasting techniques. Rather, they are concerned with how natural disaster alerts can be disseminated to the public [2]. They suggest that most difficult part in facing a natural disaster is about how to handle people when a natural disaster occurs. Additionally, most common recommendation for an early warning system is "how to evacuate." In relation with natural disaster alerts, it is also important that special attention must be taken for those who have disabilities. 
It seems to be that researchers have tried to find an appropriate approach for working on three areas: natural disaster forecaster, now-casters, or early warning systems. However, they [2] [13] [10] also still integrate their system with disaster management systems. Even Doong et al. [13] suggest that the success of a disaster mitigation concept lies in the quality of the disaster management. This shows that their approach alone is not yet adequate to handle natural disasters nor tornados. The potential reason to this case is the fact that a system for handling tornados requires very complicated mathematical analysis. Many parameters and values need to be considered and included in their calculation [4] [5] [1], and it is time consuming [11], but the system must run fast [1], that it can be used to warn people as early as possible.

As already mentioned, although the randomness of the occurrences of a natural disaster has caused difficulties in handling it, the development of every natural disaster still follows natural science characteristics and rules. Each part of a natural disaster of tornado owns specific location, time, patterns and characters. A tornado develops its twist due to hot and cold winds that move from the opposite directions. Not only the opposite winds play a role in developing a tornado, specific air pressure and air temperature are also significant contributors for a tornado's development. Yet, the difficulty to gain the measured values of those characteristics has become a new challenge in recognizing tornados before it turns up.

The steps that a tornado builds before its strong and winding wind can be regarded as a pattern. It means that the recorded data from previous tornado disasters plays a big role in recognizing it. Therefore, the data must be kept properly. The data is the important source of clues for researchers to analyze the pattern of a tornado. When patterns of tornados can be memorized, it is a strong possibility that when one of the patterns turns up, a system that can recognize patterns can be used to recognize a tornado early before it becomes a strong and destructive one. Such patterns are the most important part of mHGN for forecasting tornados hours before they strike. Unfortunately, the data provided by weather stations such as data of NOAA is not so accurate. The location of weather sensors is not exactly where the previous tornados occur. Before discussing the approach through the deployment of $\mathrm{mHGN}$, it is still important to review the fundamental concept of mHGN.

\section{Multidimensional Hierarchical Graph Neuron (mHGN)}

The purpose of describing mHGN [9] in this paper again, is to provide an easy way for readers to review its concept and its principle.

The need for solving multidimensional problems has been discussed since a long time ago. People are aware of that to handle complex problems, values taken from numerous dimensions must be considered and calculated. Otherwise, the result that comes up after the calculation - analyzing just a few parameters - cannot be considered correct. In most cases, such a condition will produce very high false positive and true negative error rates. Another issue related to solving multidimensional problems is the 
method that will be implemented. In a complex system, not only the number of dimensions is large, but how all the dimensions are interrelated to each other, or independent on one another, is often not clear.

Natural disaster system is a suitable example as a multidimensional system. Therefore, forecasting natural disasters can also considered as solving a multidimensional problem. Not only the longitude and the latitude determine the condition of natural disasters, air-temperature, air-pressure, air-humidity, wind-direction, and wind-speed also play a big role in causing natural disasters of tornados. A problem that still exists is the interdependency amongst those tangible and intangible values (industrial development, people movement, etc.). It is so difficult to figure out a formula that constitutes such interdependency. This is, therefore, a strong indication that such multidimensional problems may be solved using artificial intelligent approaches such as mHGN.

\subsection{Experiment Results}

For the experiment, each neuron (GN) is operated by a thread. Various 2D-, 3D-, 4Dand 5D-pattern recognition have been scrutinized. The compositions used in the experiment are: 15X15 mHGN, 5X15X15 mHGN, 5X5X15X15 mHGN, and $5 \mathrm{X} 5 \mathrm{X}$ X15X15 mHGN respectively. For instance, in the $15 \mathrm{X} 15$ pattern recognition the composition requires: $225+195+165+135++105+75+45+15+13+11+9+$ $7+5+3+1=1009$ neurons per value of data. As for creating patterns, binary data is used, then two values (i.e. 0 and 1) of data are required. Therefore, 2018 neurons are deployed in the 15 X15 mHGN composition. So, 2018 threads have been run in parallel during this $2 \mathrm{D}$ pattern recognition. By using threads, the activity of neurons is simulated so that the functionalities are close to the real neuron functionalities.

The experiment has worked on all the patterns of 26 alphabetical figures. Following the composition of the neurons, the alphabet patterns consist of $15 \times 15$ pixels. For the training purpose, the mHGN is first fed one-cycle with all the 26 non-distorted patterns. The order of the patterns during the training phase has been determined randomly. Then, to acquire the recognition results the mHGN is fed with a lot of randomly distorted patterns of alphabets. The recognizing accuracy is taken by calculating the average value of the results.

For the sake of the experiment, 20 distorted patterns for each alphabetical figure have been prepared. After acquiring the results, the experiment is repeated 10 times with the same steps, but each time the $\mathrm{mHGN}$ is trained with 26 patterns of alphabetical figures with randomly different order. So, for each alphabetical figure for particular percentage of distortion, in total 200 distorted patterns have been prepared as testing patterns.

There are 7 levels of distortion that have been tested, they are: $1.3 \%, 2.7 \%, 4.4 \%$, $6.7 \%, 8.0 \%, 8.9 \%$, and $10.7 \%$. These levels have been so chosen based on the number of distorted pixels. The sizes of pixels represent the factor and the non-factor of the dimension of the patterns. By doing so, we can observe all the possibilities of distortion. So, in total there are $5200(26 \times 20 \times 10)$ randomly distorted testing patterns. The following Figure 1 shows 5 samples of different orders of the training patterns: 


\begin{tabular}{|c|c|c|c|c|c|c|c|c|c|c|c|c|c|c|c|c|c|c|c|c|c|c|c|c|c|c|}
\hline 1 & E & N & W & L & I & S & P & G & H & J & D & Y & A & X & Q & R & C & M & F & V & O & T & U & K & Z & B \\
\hline 2 & R & P & J & S & O & Q & D & V & C & K & L & E & F & G & X & Y & A & T & Z & B & U & W & T & H & M & N \\
\hline 3 & G & B & H & R & Z & C & I & Y & X & S & J & K & D & A & N & T & Q & V & E & W & F & U & P & O & L & M \\
\hline 4 & L & N & I & F & R & X & B & K & O & C & T & Z & A & Y & G & V & U & H & P & J & Q & S & W & E & D & M \\
\hline 5 & C & E & T & U & N & R & H & Y & G & D & B & K & F & M & I & X & V & S & Q & J & Z & W & O & A & L & P \\
\hline
\end{tabular}

Fig. 1. Five different randomly ordered alphabets.

The following shows some results taken from testing $4.4 \%$ randomly distorted patterns, and the mHGN was previously stored with alphabetical figure patterns, and the order was IEFXMQYJHPDKTORZCUALBGVWNS. The value on the right side of each alphabet show the portion (percentage) of the pattern that is recognizable as the corresponding alphabet.

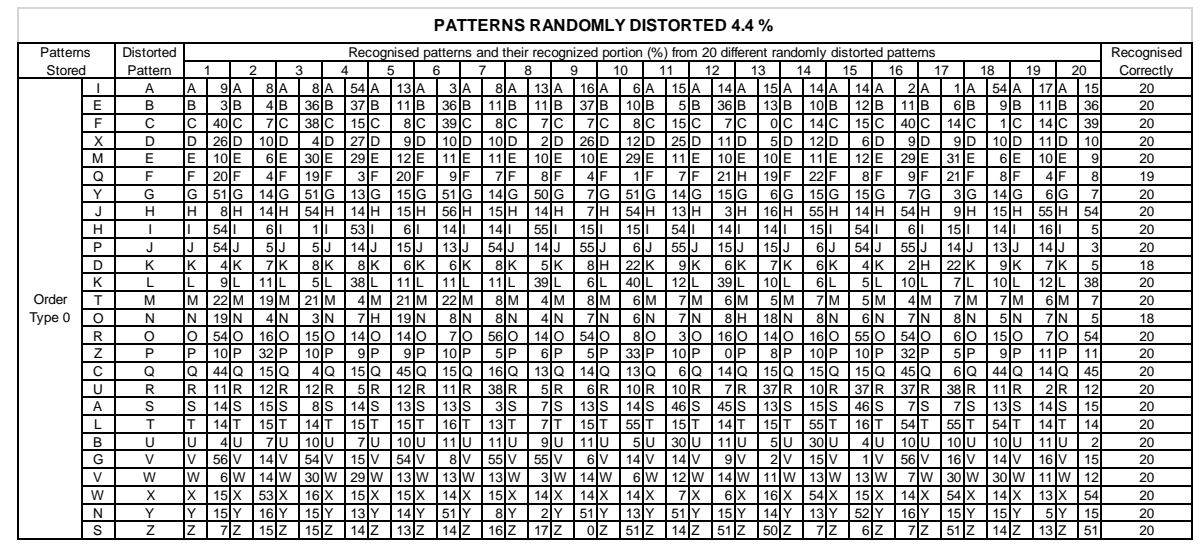

Fig. 2. The result of all the 26 alphabetical patterns that are twenty times $4.4 \%$ randomly distorted.

The following shows 10 samples of distorted patterns of the alphabetical figure of "A" taken from the experiment of recognizing 5.8\% randomly distorted patterns.

After collecting the results taken from testing 5200 patterns we can summarize how accurate the $\mathrm{mHGN}$ is, in recognizing different levels of distortion of 26 alphabets. The summary is taken based on the average accuracy values from all the steps. The following shows the summarized result taken from testing distorted patterns using five-dimensional 5X5X5X15X15 mHGN.

It can be seen from Figure 4 in the last column that the mHGN is able to recognize $91 \%$ of the $10.7 \%$ distorted patterns of 26 alphabetical figures. Some alphabetical figures of A, C, E, G, I, J, L, O, S, T, U, V, X, Y, Z, are even $100 \%$ recognizable. Other patterns of alphabetical figures of $\mathrm{H}, \mathrm{K}, \mathrm{M}, \mathrm{N}$, are not very well recognized because they are visually and physically very similar. In fact, if this architecture is used to recognize different states of the same alphabet, such as regular-A, bold-A, and italic-A as the same alphabet, then $\mathrm{mHGN}$ will be able to gain better accuracy values. 


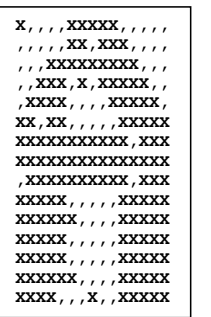

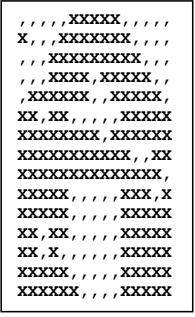

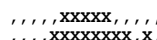

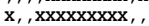

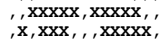

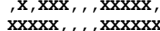

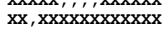

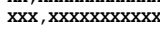

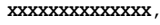

$\mathrm{xxxxx}_{\mathrm{x}}, \mathrm{x}_{,}, \mathrm{xxxxx}$

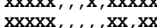

$\mathrm{xxxxx}_{1}, \ldots, \mathrm{xxxxx}$

$, \mathrm{xxxx}_{1}, \mathrm{x}_{1}, \mathrm{xxxxx}$

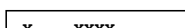

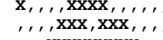

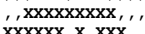

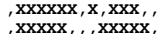

, $x_{x x x x x}, \ldots, x_{x x x x x}$

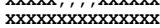

$x \times x x x x x x x x x x x$

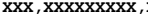

, $, \mathrm{xxx}_{1}, \ldots, \mathrm{xxxx}$

$\mathrm{xxxxx}, \ldots, \ldots, x \times x x x$

$\operatorname{xxxxx}_{\mathrm{x} x \mathrm{x} x \mathrm{n}}, \ldots, \mathrm{xxxxx}$

$x \times x \times 1,1,1, x \times x x$

$\operatorname{xxxxx}_{1},,,,, \mathrm{xxxxx}$
$\mathrm{xxxxx},,, \mathrm{x}, \mathrm{xxxx}$
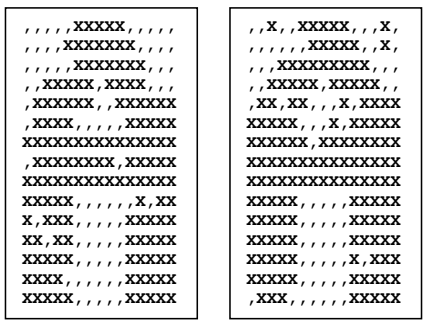

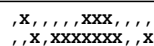

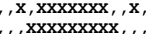

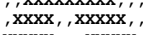

$x x x x x x x x x x x x x x x$

xxxxxxxxxxxxxxx

$x x x x x x x x, x x x x$

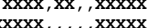

xxxxy

$\mathrm{xxxxx}, \mathrm{x}_{1}, \ldots \mathrm{xxxxx}$

$\mathrm{xxxxx}, \ldots, \ldots, \mathrm{xxxxx}$

xxxxx, , , , , $x x x x x$

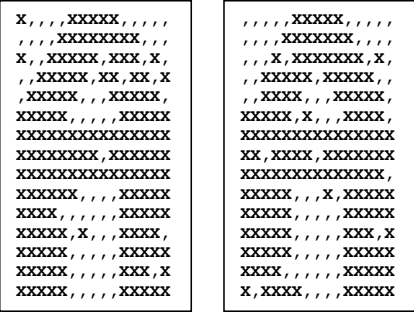

$\mathrm{xx}_{1},, \mathrm{xxxx}_{1}, \ldots$,

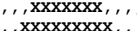

$, x \times x x x, x x x x x$,

$, x^{\prime} x x x x,,, x x x x x$

xxxxxxx, $x x_{x x x x x}$

$\mathrm{xxxxx}, \mathrm{xx}, \mathrm{xxxxxx}$

$x x x x x x x x x x x x x x x$

$\mathrm{xxxxx}, \ldots, \mathrm{xx}, \mathrm{xxx}$

$\mathrm{XxXX}_{\mathrm{X}}, \ldots, \ldots \mathrm{xX}, \mathrm{xX}$

$x_{x x x x}, \ldots, x x x x x$

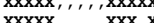

$x_{x x x x x}, \ldots, \ldots x x x x x$

Fig. 3. Ten different randomly $5.8 \%$ distorted patterns of alphabetical figure of "A"

\begin{tabular}{|c|c|c|c|c|c|c|c|c|}
\hline \multirow{2}{*}{\multicolumn{2}{|c|}{ 5X5X5X15X15 Patterns }} & \multicolumn{7}{|c|}{ Distortion (\%) } \\
\hline & & 1.3 & 2.7 & 4.4 & 6.7 & 8.0 & 8.9 & 10.7 \\
\hline \multirow{26}{*}{$\begin{array}{c}\text { Recognition } \\
\text { Accuracy for } \\
\text { Each Pattern (\%) }\end{array}$} & A & 100 & 100 & 100 & 100 & 100 & 100 & 100 \\
\hline & B & 100 & 100 & 100 & 100 & 98 & 97 & 94 \\
\hline & C & 100 & 100 & 100 & 100 & 100 & 96 & 100 \\
\hline & D & 100 & 100 & 100 & 100 & 100 & 100 & 98 \\
\hline & $E$ & 100 & 100 & 100 & 100 & 100 & 100 & 100 \\
\hline & $\mathbf{F}$ & 100 & 99 & 94 & 89 & 83 & 85 & 74 \\
\hline & $\mathbf{G}$ & 100 & 100 & 100 & 100 & 100 & 100 & 100 \\
\hline & $\mathbf{H}$ & 100 & 100 & 89 & 67 & 48 & 50 & 55 \\
\hline & I & 100 & 100 & 100 & 100 & 100 & 100 & 100 \\
\hline & $\mathbf{J}$ & 100 & 100 & 100 & 100 & 100 & 100 & 100 \\
\hline & $\mathrm{K}$ & 100 & 100 & 98 & 81 & 70 & 72 & 67 \\
\hline & $\mathbf{L}$ & 100 & 100 & 100 & 100 & 100 & 100 & 100 \\
\hline & $\mathbf{M}$ & 100 & 100 & 93 & 76 & 55 & 66 & 49 \\
\hline & $\mathbf{N}$ & 100 & 100 & 97 & 77 & 63 & 60 & 55 \\
\hline & 0 & 100 & 100 & 100 & 100 & 100 & 100 & 100 \\
\hline & $\mathbf{P}$ & 100 & 99 & 87 & 79 & 80 & 81 & 81 \\
\hline & $\mathbf{Q}$ & 100 & 100 & 100 & 100 & 100 & 94 & 99 \\
\hline & $\mathbf{R}$ & 100 & 100 & 100 & 95 & 100 & 99 & 95 \\
\hline & $\mathrm{S}$ & 100 & 100 & 100 & 100 & 100 & 100 & 100 \\
\hline & $\mathbf{T}$ & 100 & 100 & 100 & 100 & 100 & 100 & 100 \\
\hline & $\mathbf{U}$ & 100 & 100 & 100 & 100 & 100 & 100 & 100 \\
\hline & $\mathbf{V}$ & 100 & 100 & 100 & 100 & 100 & 100 & 100 \\
\hline & W & 100 & 100 & 100 & 100 & 99 & 98 & 92 \\
\hline & $\mathbf{X}$ & 100 & 100 & 100 & 100 & 100 & 100 & 100 \\
\hline & $\mathbf{Y}$ & 100 & 100 & 100 & 100 & 100 & 100 & 100 \\
\hline & $\mathbf{Z}$ & 100 & 100 & 100 & 100 & 100 & 100 & 100 \\
\hline Average & & 100 & 100 & 98 & 95 & 92 & 92 & 91 \\
\hline
\end{tabular}

Fig. 4. The summary of the result using 5X5X5X15X15 mHGN [14] 
The following figure shows the differences of recognition accuracy amongst $15 \mathrm{X} 15$, $5 \times 15 X 15,5 \times 5 X 15 \times 15$, and $5 \times 5 \times 5 X 15 X 15$ mHGN architectures when recognizing $10.7 \%$ distorted patterns of alphabets.

\begin{tabular}{|c|c|c|c|c|c|}
\hline \multirow{2}{*}{\multicolumn{2}{|c|}{ Comparison Result }} & \multicolumn{4}{|c|}{ Distortion $=10.7 \%$} \\
\hline & & \multirow{2}{*}{$\begin{array}{c}15 \times 15 \\
99 \\
\end{array}$} & \multirow{2}{*}{$\begin{array}{c}\mathbf{5 X 1 5 X 1 5} \\
100 \\
\end{array}$} & \multirow{2}{*}{$\frac{5 \times 5 \times 15 X 15}{100}$} & \multirow{2}{*}{$\frac{5 \times 5 \times 5 \times 15 \times 15}{100}$} \\
\hline \multirow{26}{*}{$\begin{array}{c}\text { Recognition } \\
\text { Accuracy for } \\
\text { Each Pattern (\%) }\end{array}$} & A & & & & \\
\hline & B & 58 & 69 & 92 & 94 \\
\hline & C & 67 & 93 & 94 & 100 \\
\hline & D & 78 & 92 & 94 & 98 \\
\hline & $\mathbf{E}$ & 85 & 80 & 100 & 100 \\
\hline & $\mathbf{F}$ & 61 & 71 & 81 & 74 \\
\hline & $\mathbf{G}$ & 87 & 98 & 100 & 100 \\
\hline & $\mathrm{H}$ & 23 & 63 & 69 & 55 \\
\hline & I & 95 & 100 & 100 & 100 \\
\hline & $\mathbf{J}$ & 77 & 95 & 100 & 100 \\
\hline & $\mathbf{K}$ & 68 & 59 & 84 & 67 \\
\hline & $\mathbf{L}$ & 50 & 80 & 100 & 100 \\
\hline & M & 38 & 36 & 35 & 49 \\
\hline & $\mathbf{N}$ & 53 & 42 & 63 & 55 \\
\hline & 0 & 100 & 100 & 100 & 100 \\
\hline & $\mathbf{P}$ & 61 & 59 & 75 & 81 \\
\hline & $\mathbf{Q}$ & 63 & 73 & 73 & 99 \\
\hline & $\mathbf{R}$ & 79 & 90 & 95 & 95 \\
\hline & $\mathrm{S}$ & 78 & 97 & 100 & 100 \\
\hline & $\mathbf{T}$ & 93 & 95 & 100 & 100 \\
\hline & $\mathbf{U}$ & 89 & 84 & 85 & 100 \\
\hline & $\mathbf{V}$ & 100 & 100 & 100 & 100 \\
\hline & $\mathbf{W}$ & 75 & 82 & 98 & 92 \\
\hline & $\mathbf{X}$ & 85 & 100 & 100 & 100 \\
\hline & $\mathbf{Y}$ & 100 & 100 & 100 & 100 \\
\hline & $\mathbf{Z}$ & 99 & 100 & 100 & 100 \\
\hline \multicolumn{2}{|l|}{ Average } & 75 & 83 & 90 & 91 \\
\hline
\end{tabular}

Fig. 5. Differences of recognition accuracy amongst four different architectures

\subsection{Time-Series in Pattern Recognition}

Recognizing patterns of time series problem utilizes data that have previously been recorded regularly in timely manner [14]. For instance, if the parameter that needs to be recorded is a single value, and the recording step is every six hours, then there will be 4 values recorded every day. In order to constructs the recorded values as a pattern, the data representation of the recorded values need to be developed so, that they can fit into a pattern recognition architecture. The following figure shows six ways of representing recorded data for 8 values of measurement.

Definition: The distance between two values is the number of different bits between them. For instance, the distance between 001 and 110 is 3, whereas the distance between 00000001 and 10000000 is 2. Some people know it as Hamming Distance.

It can be seen from figure 6 that the data (value) is represented using binary numbers, and there are six possible data representations (Ver1 till Ver6). For the Ver1 (Binary Code Decimal), the distance between adjacent values varies. It is therefore not suitable for mHGN. For the Ver2 (Grey Code), the distance between two adjacent values is constant, which is one. However, the distance between Value 2 and 7 is also one. This is not suitable, as for $\mathrm{mHGN}$ the distance of 1 also means that the two values are very 
close to each other. In fact, value 2 and 7 are very different and very far from each other. Again, this is not suitable for mHGN. For the Ver3 and Ver4 (Ring Counter), the distance between any two values is constant, which is two. These are again not suitable for mHGN. For the Ver5 and Ver6 (Johnson Counter) the distance between adjacent values is constant, which is one. Additionally, the distance between any two values is linear with the value differences.

\begin{tabular}{|c|c|c|c|c|c|c|}
\hline Value & Ver1 & Ver2 & Ver3 & Ver4 & Ver5 & Ver6 \\
\hline 1 & 000 & 000 & 00000001 & 10000000 & 00000001 & 10000000 \\
\hline 2 & 001 & 001 & 00000010 & 01000000 & 00000011 & 11000000 \\
\hline 3 & 010 & 011 & 00000100 & 00100000 & 00000111 & 11100000 \\
\hline 4 & 011 & 010 & 00001000 & 00010000 & 00001111 & 11110000 \\
\hline 5 & 100 & 110 & 00010000 & 00001000 & 00011111 & 11111000 \\
\hline 6 & 101 & 111 & 00100000 & 00000100 & 00111111 & 11111100 \\
\hline 7 & 110 & 101 & 01000000 & 00000010 & 01111111 & 11111110 \\
\hline 8 & 111 & 100 & 10000000 & 00000001 & 11111111 & 11111111 \\
\hline
\end{tabular}

Fig. 6. Six examples of data representation for 8 levels of value

It seems to be that the Ver5 and Ver6 are the most suitable data representation that can be used with mHGN. However, such data representation will not efficiently utilize the binary combination. Using 3-bit data, only $3 / 8$ or 0.375 is the occupation ratio. Using 4-bit data is the occupation ratio $4 / 16$ or 0.25 . The occupation ratio is $5 / 32$ or 0.15625 when using 5-bit data. The facts show that the Ver5 and Ver6 data representation will produce less occupation ratio, the more bits is used. This is an indication that due to such an occupation ratio the pattern recognizer will have less recognition accuracy, the more bits is used. So, these are again not suitable for mHGN. The following is a better data representation.

In figure 7, there are three examples of 3-bit, 4-bit, and 5-bit data representation. It is shown that the distance between any adjacent levels in all samples is constant, which is one. Furthermore, between any two values which have value difference of two, the distance is also constant, which is two. Last, the distance between any two values which have value difference of three, the distance is again constant, which is three. For mHGN, such constant distances of 1, 2, and 3 are adequate to be used in tornado recognition architecture. Another characteristic of these data representations is that the representation is cyclic. It means that, if it is required the order of binary representation can be modified circularly without affecting the characteristic related to the distances. Using such better data representations, in all examples is the occupation ratio constantly 0.75 . With such a constant occupation ratio the pattern recognizer will have constant recognition accuracy, regardless how many bits of data representation is used.

The figure 8 shows an example of recorded data taken from a single location measurement and each value has 3 X5-bit values. 


\begin{tabular}{|c|c|c|c|}
\hline Value & 3-bit & 4-bit & 5-bit \\
\hline $\mathbf{1}$ & 101 & 0101 & 00101 \\
\hline $\mathbf{2}$ & 100 & 0100 & 00100 \\
\hline $\mathbf{3}$ & 110 & 0110 & 00110 \\
\hline $\mathbf{4}$ & 010 & 1110 & 01110 \\
\hline $\mathbf{5}$ & 011 & 1111 & 01111 \\
\hline $\mathbf{6}$ & 001 & 1101 & 01101 \\
\hline $\mathbf{7}$ & & 1001 & 01001 \\
\hline $\mathbf{8}$ & & 1000 & 01000 \\
\hline $\mathbf{9}$ & & 1010 & 01010 \\
\hline $\mathbf{1 0}$ & & 0010 & 11010 \\
\hline $\mathbf{1 1}$ & & 0011 & 11011 \\
\hline $\mathbf{1 2}$ & & 0001 & 11001 \\
\hline $\mathbf{1 3}$ & & & 11101 \\
\hline $\mathbf{1 4}$ & & & 11100 \\
\hline $\mathbf{1 5}$ & & & 11110 \\
\hline $\mathbf{1 6}$ & & & 10110 \\
\hline $\mathbf{1 7}$ & & & $\mathbf{1 0 1 1 1}$ \\
\hline $\mathbf{1 8}$ & & & 10101 \\
\hline $\mathbf{1 9}$ & & & 10001 \\
\hline $\mathbf{2 0}$ & & & 10000 \\
\hline $\mathbf{2 1}$ & & & 10010 \\
\hline $\mathbf{2 2}$ & & & 00010 \\
\hline $\mathbf{2 3}$ & & & $\mathbf{0 0 0 1 1}$ \\
\hline $\mathbf{2 4}$ & & & 00001 \\
\hline & & & \\
\hline
\end{tabular}

Fig. 7. Three examples of a better data representation for 3-, 4-, and 5-bit binary values

$\begin{array}{cccccccccc}1 & 0 & 1 & 1 & 0 & 0 & 1 & 1 & 0 & 0 \\ 1 & 1 & 1 & 1 & 0 & 1 & 1 & 1 & 1 & 0 \\ 0 & 0 & 0 & 1 & 1 & 1 & 1 & 1 & 0 & 1 \\ 1 & 1 & 1 & 0 & 0 & 1 & 0 & 0 & 1 & 0 \\ 1 & 0 & 0 & 1 & 0 & 1 & 1 & 0 & 0 & 0 \\ 1 & 0 & 1 & 0 & 1 & 0 & 1 & 1 & 0 & 0 \\ 1 & 1 & 1 & 0 & 1 & 1 & 1 & 1 & 1 & 1 \\ 0 & 1 & 1 & 1 & 0 & 0 & 0 & 1 & 0 & 1 \\ 1 & 1 & 0 & 0 & 1 & 1 & 1 & 0 & 1 & 1 \\ 1 & 1 & 0 & 0 & 0 & 0 & 0 & 1 & 0 & 1 \\ 0 & 1 & 0 & 0 & 0 & 0 & 1 & 0 & 1 & 1 \\ 0 & 1 & 1 & 1 & 1 & 1 & 1 & 0 & 1 & 1 \\ 1 & 0 & 1 & 0 & 1 & 1 & 1 & 1 & 1 & 0 \\ 0 & 1 & 1 & 1 & 1 & 1 & 0 & 0 & 0 & 1 \\ 0 & 1 & 1 & 0 & 1 & 1 & 0 & 0 & 1 & 1 \\ 00.00 & 03.00 & 06.00 & 09.00 & 12.00 & 15.00 & 18.00 & 21.00 & 00.00 & 03.00\end{array}$

Fig. 8. Time series data of 15-bit values build a 2D-Pattern 
It can be seen from figure 8 that the recorded values from parameter of 15-bit data construct a two-dimensional pattern of 10X15 architecture. Utilizing these recorded data, the pattern recognizer can forecast a tornado 6 hours earlier, when the same tornado occurs again. It means that if values have been recorded and the same pattern is recognized by the pattern recognizer, then the tornado is forecasted to occur again within 6-hour time with around $90 \%$ of accuracy.

\section{$4 \quad$ Multidimensional Graph Neuron for Tornado Forecasting}

In the previous section, time series value is described and represented so, that it can be forecasted through utilizing a pattern recognition, such as mHGN. In case of tornado forecasting, single parameter in a location, such as air-pressure, is not the only value that determine the occurrence of a tornado in the location within 6-hour time. Several other parameters, such as wind-speed, wind-direction, air-temperature, and air-humidity, play a big role in the occurrences as well. It means that the number of levels or a measured value will increase according to the number of parameters. In case 5 parameters need to be measured and each parameter contains 5-bit value, the required pattern structure would be $10 \mathrm{X} 25$.

Also described in the previous section that measuring a parameter at particular point of location for several periods of time will generate a two dimensional pattern. If a series of points of the location need to be measured for several period of time, then the measured values will become a three dimensional pattern. The following figure depicts how some part of it will look like.

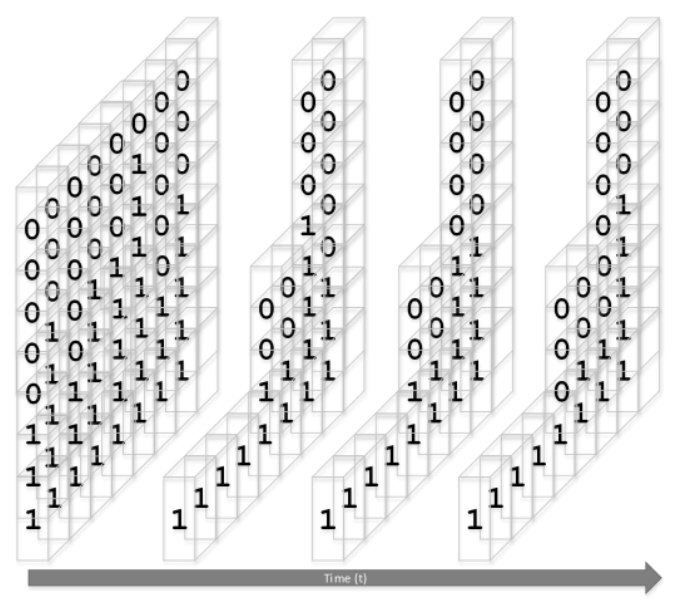

Fig. 9. A row of data of 8-bit value build a 3D-Pattern

Also described in the previous section that measuring parameters at particular point of location for several periods of time will generate a two dimensional pattern. If a series and linear of locations need to be measured for several periods of time, then the measured values will become a three dimensional pattern. If the location that need to 
be measured is an 2D area, then the measured values will generate a $4 \mathrm{D}$ pattern. Furthermore, if the location that need to be measured is a $3 \mathrm{D}$ area, then the measured values will generate a $5 \mathrm{D}$ pattern.

\subsection{The Architecture of mHGN for Time-Series Tornado Data}

The utilization of mHGN has introduced a new approach that a local tornado forecast can be operated using small and cheap components. The values of air-temperature, airhumidity, air-pressure, wind-speed, and wind-direction can be gained through ordinary sensors. The area that is covered by those sensors can be a 3D area, because such small sensors can be easily mounted in valleys or hills, or even vehicles. The sensors can be embedded in a tiny computer, such as Raspberry Pi. The tiny computer will be responsible to run several GNs. The values taken from the sensors will then be worked out within the GNs. The connectivity of neurons is developed within a tiny computer and through the interconnectivity of the tiny computers.

In short, to build a tornado forecast for particular location, five parameters need to be measured. They are: wind-speed, wind-direction, air-temperature, air-humidity, and air-pressure. So, if one parameter is represented through 5-bit binary data, then for the measurement of 5 parameters 25-bit data is needed. For the time series, 15 series of measurement will be carried out. For an area that needs to be protected by mHGN, $3 \mathrm{X} 3 \mathrm{X} 3$ measurement points will be deployed. So, the mHGN dimension will be $3 \mathrm{X} 3 \mathrm{X} 3 \mathrm{X} 25 \mathrm{X} 15$.

The positions of the $3 \mathrm{X} 3 \mathrm{X} 3 \mathrm{GNs}$ will form a cylinder shape. In the cylinder, there will be three layers of circles. Each layer contains 9 GNs, in which 8 GNs will be on the border of the circle, and one GN will be located in the centre of the circle. The following figure shows the architecture of the positions of the sensors.

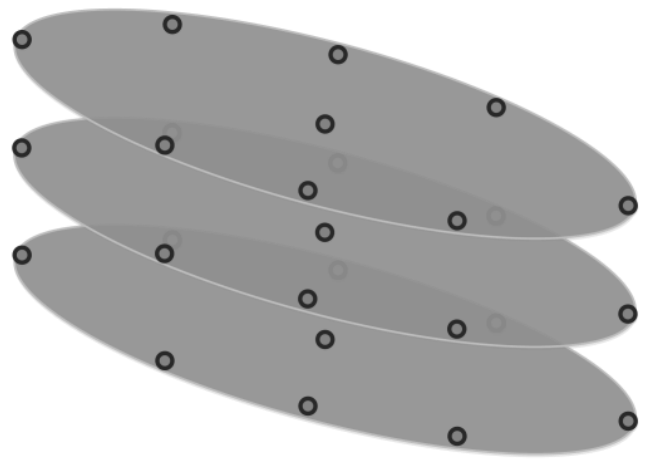

Fig. 10. The architecture of $3 X 3 X 3$ sensors

The cylinder shape of the architecture has been chosen so, that mHGN still has an ability to recognize the same tornado pattern but developed with the direction different from the ones already stored. For the purpose of training, patterns from the previous tornados will be stored in the mHGN. Each pattern of a tornado will then be stored in 
mHGN eight times, following the number of eight major compass directions. It will look like as if the mHGN has stored 8 patterns of tornados. By having eight patterns for each tornado stored in $\mathrm{mHGN}$, whenever the same characteristics of a tornado turn up but from different direction from the already stored ones, mHGN will be able to recognize it.

\subsection{Data Handlings for Real Tornados}

Two deadliest tornados occurred quite recently are the tornado that struck Joplin, Missouri on May 22, 2011 and the one in Hackleburg-Phil Campbell, Alabama on April 27, 2011. To store the circumstances, several parameters in these areas need to be stored in mHGN. Fortunately, the National Oceanic and Atmospheric Administration (NOAA) provides lots of data of: air-temperature, air-humidity, air-pressure, windspeed, wind-direction in most areas of the US. These data will be the major source for mHGN to store previous occurrences of tornados. In the case of Joplin, the following are several locations of stations that have recorded those data from their sensors including the map in the state of Missouri.

The following is the list of tornados scale F5/EF5 (the strongest) occurred In the US. The indicator F stands for Fujita and EF stands for extended Fujita. The scale has been named the same as the meteorologist Ted Fujita, who developed the scale.

1. May 4, 2007, Greensburg, Kansas

2. May 25, 2008, Parkersburg-New Hartford, Iowa

3. April 27, 2011, Philadelphia-Preston, Mississippi

4. April 27, 2011, Smithville, Mississippi

5. April 27 2011, Hackleburg-Phil Campbell, Alabama

6. April 27 2011, Tuscaloosa-Birmingham, Alabama

7. April 27, 2011, Rainsville-Sylvania, Alabama

8. May 22 2011, Joplin, Missouri

9. May 24, 2011, El Reno-Piedmont, Oklahoma

10. May 24, 2011, Chickasha-Blanchard-Newcastle, Oklahoma

11. May 24, 2011, Washington-Goldsby, Oklahoma

12. May 20, 2013, Moore, Oklahoma

13. May 31, 2013, El Reno, Oklahoma

14. April 27, 2014, Vilonia, Arkansas

It can be seen from the map above, that based on the close location and the same time frame the data of Joplin's tornado can be used to test the Oklahoma's tornados (five tornados). Similarly, the data of Philadelphia-Preston's tornado or Smithville's tornado can be used to test Alabama's tornados (three tornados). 


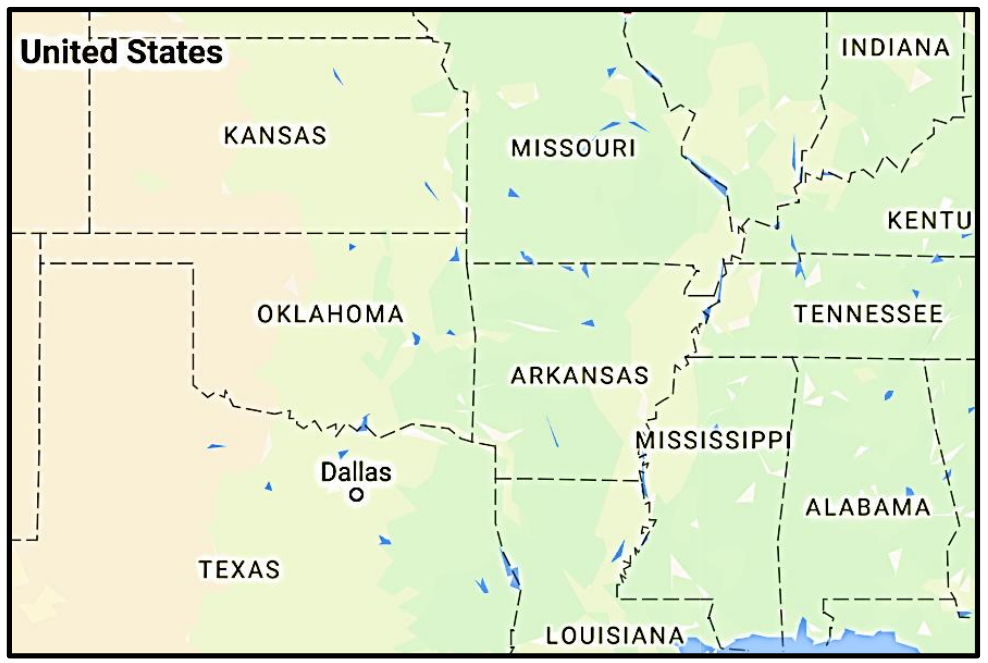

Fig. 11. The locations of F5/EF5 tornados

Daily Weather History Graph
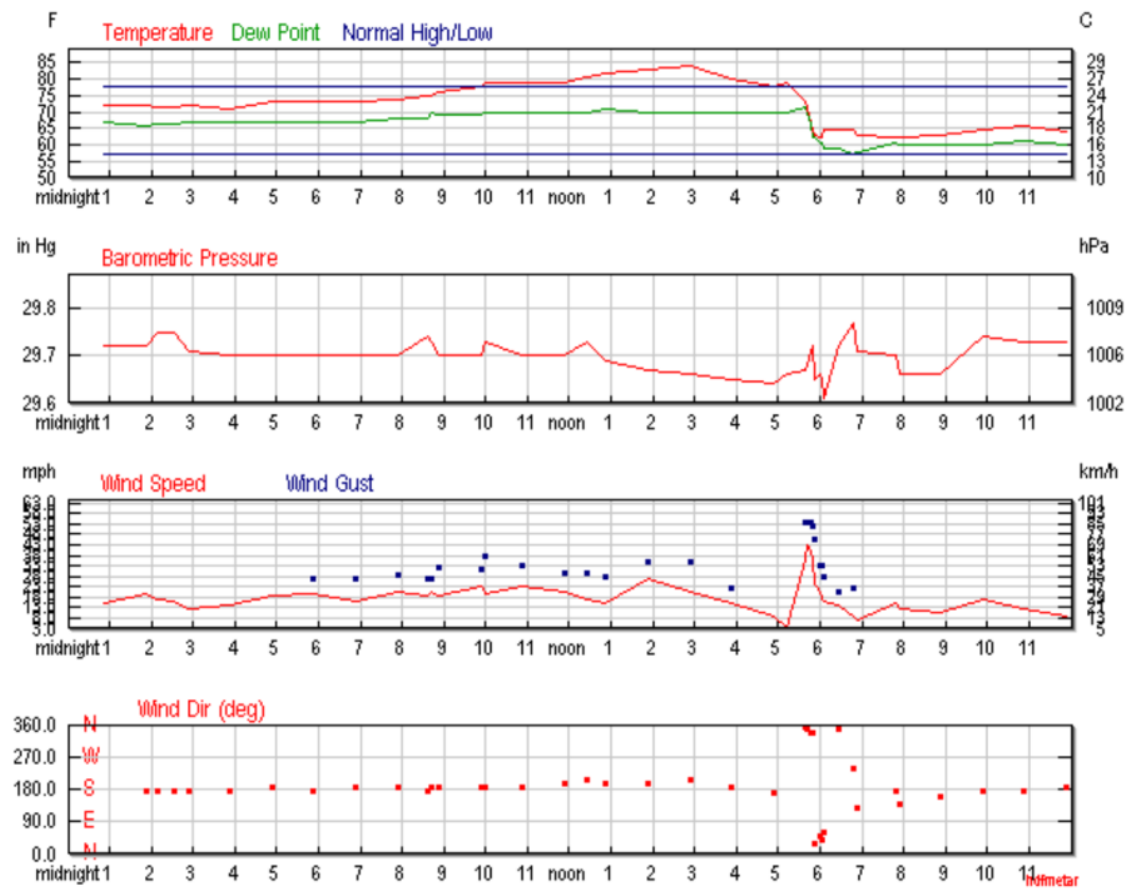

Fig. 12. The Weather data of Joplin Station on May 22, 2011 
Hourly Weather History \& Observations

\begin{tabular}{|c|c|c|c|c|c|c|c|c|c|c|c|c|}
\hline $\begin{array}{l}\text { Time } \\
\text { (CDT) }\end{array}$ & Temp. & $\begin{array}{l}\text { Heat } \\
\text { Index }\end{array}$ & $\begin{array}{l}\text { Dew } \\
\text { Point }\end{array}$ & Humidity & Pressure & Visibility & $\begin{array}{l}\text { Wind } \\
\text { Dir }\end{array}$ & Wind Speed & Gust Speed & Precip & Events & Conditions \\
\hline $\begin{array}{l}12: 53 \\
\text { AM }\end{array}$ & $22.2^{\circ} \mathrm{C}$ & - & $19.4^{\circ} \mathrm{C}$ & $84 \%$ & $1006.4 \mathrm{hPa}$ & $12.9 \mathrm{~km}$ & South & $\begin{array}{l}24.1 \mathrm{~km} / \mathrm{h} / \\
6.7 \mathrm{~m} / \mathrm{s}\end{array}$ & - & N/A & & Clear \\
\hline 1:53 AM & $22.2^{\circ} \mathrm{C}$ & - & $18.9^{\circ} \mathrm{C}$ & $81 \%$ & $1006.4 \mathrm{hPa}$ & $12.9 \mathrm{~km}$ & South & $\begin{array}{l}31.5 \mathrm{~km} / \mathrm{h} / \\
8.7 \mathrm{~m} / \mathrm{s}\end{array}$ & $\begin{array}{l}\frac{42.6 \mathrm{~km} / \mathrm{h} /}{11.8 \mathrm{~m} / \mathrm{s}} \\
\end{array}$ & N/A & & Partly Cloudy \\
\hline 2:10 AM & $22.0^{\circ} \mathrm{C}$ & - & $19.0^{\circ} \mathrm{C}$ & $83 \%$ & $1007.3 \mathrm{hPa}$ & $12.9 \mathrm{~km}$ & South & $\begin{array}{l}27.8 \mathrm{~km} / \mathrm{h} / \\
7.7 \mathrm{~m} / \mathrm{s}\end{array}$ & - & N/A & & Mostly Cloudy \\
\hline 2:33 AM & $22.0^{\circ} \mathrm{C}$ & - & $19.0^{\circ} \mathrm{C}$ & $83 \%$ & $1007.3 \mathrm{hPa}$ & $12.9 \mathrm{~km}$ & South & $\begin{array}{l}25.9 \mathrm{~km} / \mathrm{h} / \\
7.2 \mathrm{~m} / \mathrm{s}\end{array}$ & $\cdot$ & N/A & & Scattered Clouds \\
\hline $2: 53 \mathrm{AM}$ & $22.2^{\circ} \mathrm{C}$ & - & $19.4^{\circ} \mathrm{C}$ & $84 \%$ & $1005.9 \mathrm{hPa}$ & $11.3 \mathrm{~km}$ & South & $\begin{array}{l}20.4 \mathrm{~km} / \mathrm{h} / \\
5.7 \mathrm{~m} / \mathrm{s}\end{array}$ & $\begin{array}{l}37.0 \mathrm{~km} / \mathrm{h} / \\
10.3 \mathrm{~m} / \mathrm{s}\end{array}$ & N/A & & Clear \\
\hline 3:53 AM & $21.7^{\circ} \mathrm{C}$ & - & $19.4^{\circ} \mathrm{C}$ & $87 \%$ & $1005.8 \mathrm{hPa}$ & $11.3 \mathrm{~km}$ & South & $\begin{array}{l}22.2 \mathrm{~km} / \mathrm{h} / \\
6.2 \mathrm{~m} / \mathrm{s}\end{array}$ & - & N/A & & Partly Cloudy \\
\hline 4:53 AM & $22.8^{\circ} \mathrm{C}$ & - & $19.4^{\circ} \mathrm{C}$ & $81 \%$ & $1005.7 \mathrm{hPa}$ & $11.3 \mathrm{~km}$ & South & $\begin{array}{l}29.6 \mathrm{~km} / \mathrm{h} / \\
8.2 \mathrm{~m} / \mathrm{s}\end{array}$ & $\begin{array}{l}40.7 \mathrm{~km} / \mathrm{h} / \\
11.3 \mathrm{~m} / \mathrm{s}\end{array}$ & N/A & & Overcast \\
\hline 5:53 AM & $22.8^{\circ} \mathrm{C}$ & - & $19.4^{\circ} \mathrm{C}$ & $81 \%$ & $1005.5 \mathrm{hPa}$ & $11.3 \mathrm{~km}$ & South & $\begin{array}{l}31.5 \mathrm{~km} / \mathrm{h} / \\
8.7 \mathrm{~m} / \mathrm{s}\end{array}$ & $\begin{array}{l}42.6 \mathrm{~km} / \mathrm{h} / \\
11.8 \mathrm{~m} / \mathrm{s}\end{array}$ & N/A & & Overcast \\
\hline 6:53 AM & $22.8^{\circ} \mathrm{C}$ & - & $19.4^{\circ} \mathrm{C}$ & $81 \%$ & $1005.6 \mathrm{hPa}$ & $9.7 \mathrm{~km}$ & South & $\begin{array}{l}25.9 \mathrm{~km} / \mathrm{h} / \\
7.2 \mathrm{~m} / \mathrm{s}\end{array}$ & $\begin{array}{l}42.6 \mathrm{~km} / \mathrm{h} / \\
11.8 \mathrm{~m} / \mathrm{s}\end{array}$ & N/A & & Haze \\
\hline 7:53 AM & $23.3^{\circ} \mathrm{C}$ & - & $20.0^{\circ} \mathrm{C}$ & $82 \%$ & $1005.8 \mathrm{hPa}$ & $9.7 \mathrm{~km}$ & South & $\begin{array}{l}33.3 \mathrm{~km} / \mathrm{h} / \\
9.3 \mathrm{~m} / \mathrm{s}\end{array}$ & $\begin{array}{l}46.3 \mathrm{~km} / \mathrm{h} / \\
12.9 \mathrm{~m} / \mathrm{s}\end{array}$ & N/A & & Haze \\
\hline 8:36 AM & $24.0^{\circ} \mathrm{C}$ & - & $20.0^{\circ} \mathrm{C}$ & $78 \%$ & $1007.0 \mathrm{hPa}$ & $9.7 \mathrm{~km}$ & South & $\begin{array}{l}29.6 \mathrm{~km} / \mathrm{h} / \\
8.2 \mathrm{~m} / \mathrm{s}\end{array}$ & $\begin{array}{l}42.6 \mathrm{~km} / \mathrm{h} / \\
11.8 \mathrm{~m} / \mathrm{s}\end{array}$ & N/A & & Haze \\
\hline 8:43 AM & $24.0^{\circ} \mathrm{C}$ & - & $21.0^{\circ} \mathrm{C}$ & $83 \%$ & $1006.7 \mathrm{hPa}$ & $9.7 \mathrm{~km}$ & South & $\begin{array}{l}33.3 \mathrm{~km} / \mathrm{h} / \\
9.3 \mathrm{~m} / \mathrm{s}\end{array}$ & $\begin{array}{l}42.6 \mathrm{~km} / \mathrm{h} / \\
11.8 \mathrm{~m} / \mathrm{s}\end{array}$ & N/A & & Haze \\
\hline
\end{tabular}

Fig. 13. The Detailed Weather data of Joplin Station on May 22, 2011
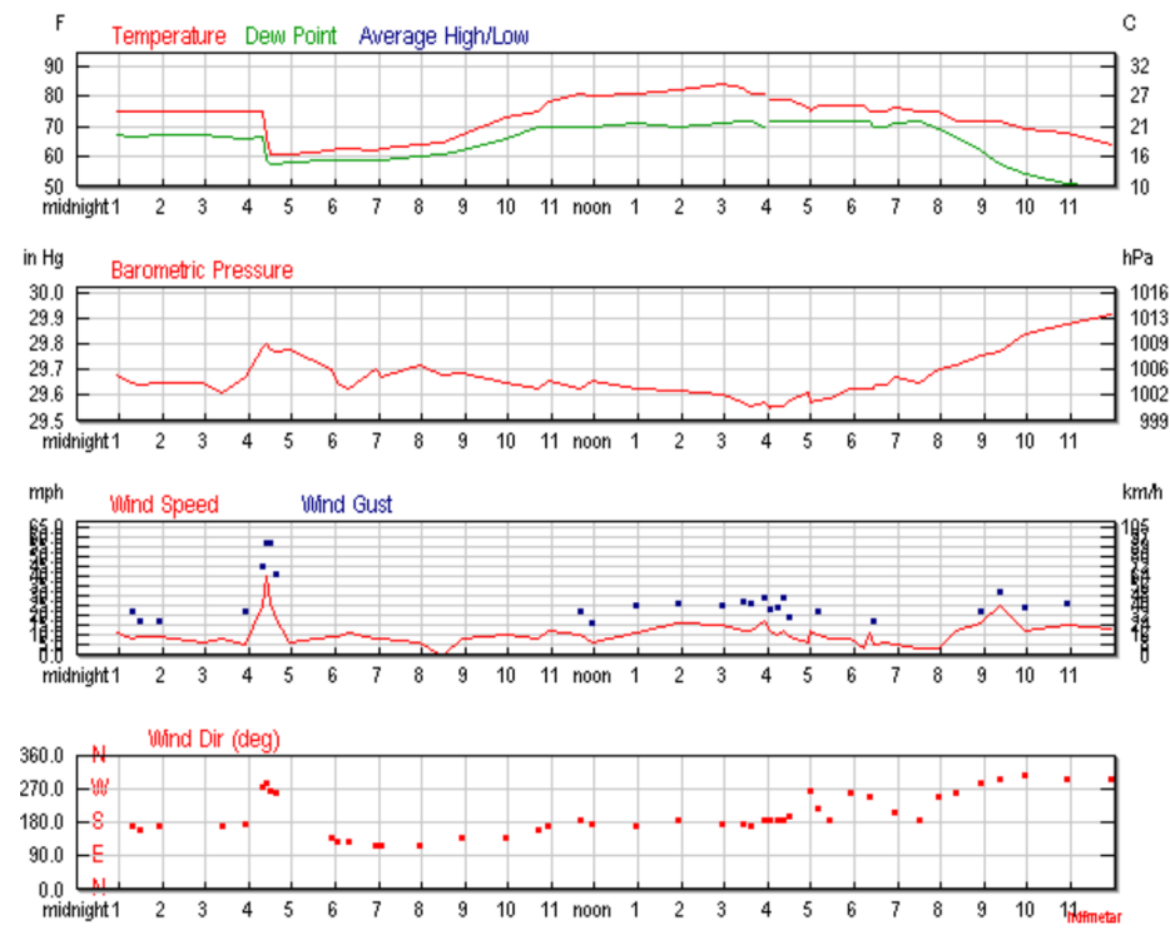

Fig. 14. The Weather data of Philadelphia-Preston Station on April 27, 2011 
In order to collect the suitable data that fit with the architecture of mHGN, the locations of the chosen weather stations that the data will be taken from, must build a figure like a circle, and the middle weather station must be located in the area in which a tornado has hit. The following is an excerpt of the data taken from a weather station Joplin in the State of Missouri.

\section{Discussion}

As is the case with pattern recognition of alphabets, patterns are more or less different to one another. However, in time series measurement data patterns, which are constructed from the measured values of the sensors, can be very similar to one another. Therefore, data representation of measured values before data is fed to the architecture of mHGN plays a big role in having very accurate results. False positive and true negative rate will also be indications to determine the quality of mHGN in forecasting natural disastesr.

The data that will be used to validate this work will be the data taken from different cities and different countries. As mHGN is trained one-cycle only, it is a challenge to choose which data is the right data for the training purpose, or the data is the consolidated data from a number of occurrences. When the appropriate training data has been applied, mHGN will then have a capability to forecast a tornado.

The main thing that needs to be developed for supporting the tornado forecasting technology is a sequence of binary values. Since the analog values taken from sensors (temperature, humidity, pressure, wind speed, and wind direction) need to be precise, so at least 5-bit binary values are required.

The requirements for the sequence of the 5-bit binary values are:

1. The Hamming Distance of any binary value to its first adjacent neighbour value is 1 .

2. The Hamming Distance of any binary value to its second adjacent neighbour value is 2 .

3. The Hamming Distance of any binary value to its third adjacent neighbour value is 3 .

4. The sequence should be cyclic, which means that any binary-value can be either the first or the last member of the sequence.

The following are those mentioned binary values (Fig. 15).

It can be seen from the table above that all four requirements are fulfilled. To prove that the sequence is cyclic, it can be done through inserting the value at the index of 1 underneath the value at the index of 24 . It can then be seen that all three requirements of the sequence (about Hamming Distances) are still fulfilled. So, after the index of 24 , the sequence can be continued with the values of the index of 1 , and 2 , and 3 , and so forth. 


\begin{tabular}{|c|c|c|c|}
\hline Index & Value & Index & Value \\
\hline $\mathbf{1}$ & 00101 & $\mathbf{1 3}$ & 11101 \\
\hline $\mathbf{2}$ & $\mathbf{0 0 1 0 0}$ & $\mathbf{1 4}$ & $\mathbf{1 1 1 0 0}$ \\
\hline $\mathbf{3}$ & 00110 & $\mathbf{1 5}$ & 11110 \\
\hline $\mathbf{4}$ & 01110 & $\mathbf{1 6}$ & 10110 \\
\hline $\mathbf{5}$ & 01111 & $\mathbf{1 7}$ & 10111 \\
\hline $\mathbf{6}$ & 01101 & $\mathbf{1 8}$ & 10101 \\
\hline $\mathbf{7}$ & 01001 & $\mathbf{1 9}$ & 10001 \\
\hline $\mathbf{8}$ & 01000 & $\mathbf{2 0}$ & $\mathbf{1 0 0 0 0}$ \\
\hline $\mathbf{9}$ & 01010 & $\mathbf{2 1}$ & 10010 \\
\hline $\mathbf{1 0}$ & 11010 & $\mathbf{2 2}$ & 00010 \\
\hline $\mathbf{1 1}$ & $\mathbf{1 1 0 1 1}$ & $\mathbf{2 3}$ & $\mathbf{0 0 0 1 1}$ \\
\hline $\mathbf{1 2}$ & 11001 & $\mathbf{2 4}$ & 00001 \\
\hline
\end{tabular}

Fig. 15. The binary values for 5-bit data

\begin{tabular}{|c|c|c|c|c|c|c|c|c|c|c|c|c|c|c|c|c|c|c|c|c|c|c|c|c|}
\hline & 0010 & & & & 01 & & & & & & & & & & & & 10111 & 101] & & 10000 & & & & 0001 \\
\hline 00101 & 0 & 1 & 2 & 3 & 2 & 1 & 2 & 3 & 4 & 5 & 4 & 3 & 2 & 3 & 4 & 3 & 2 & 1 & 2 & 3 & 4 & 3 & 2 & 1 \\
\hline 0100 & 1 & 0 & 1 & 2 & 3 & 2 & 3 & 2 & 3 & 4 & 5 & 4 & 3 & 2 & 3 & 2 & 3 & 2 & 3 & 2 & 3 & 2 & 3 & 2 \\
\hline 1110 & 2 & 1 & 0 & 1 & 2 & 3 & 4 & 3 & 2 & 3 & 4 & 5 & 4 & 3 & 2 & 1 & 2 & 3 & 4 & 3 & 2 & 1 & 2 & 3 \\
\hline 110 & 3 & 2 & 1 & 0 & 1 & 2 & 3 & 2 & 1 & 2 & 3 & 4 & 3 & 2 & 1 & 2 & 3 & 4 & 5 & 4 & 3 & 2 & 3 & 4 \\
\hline 1111 & 2 & 3 & 2 & 1 & 0 & 1 & 2 & 3 & 2 & 3 & 2 & 3 & 2 & 3 & 2 & 3 & 2 & 3 & 4 & 5 & 4 & 3 & 2 & 3 \\
\hline 1101 & 1 & 2 & 3 & 2 & 1 & 0 & 1 & 2 & 3 & 4 & 3 & 2 & 1 & 2 & 3 & 4 & 3 & 2 & 3 & 4 & 5 & 4 & 3 & 2 \\
\hline 1001 & 2 & 3 & 4 & 3 & 2 & 1 & 0 & 1 & 2 & 3 & 2 & 1 & 2 & 3 & 4 & 5 & 4 & 3 & 2 & 3 & 4 & 3 & 2 & 1 \\
\hline 1000 & 3 & 2 & 2 & 2 & 3 & 2 & 1 & 0 & 1 & 2 & 3 & 2 & 3 & 2 & 3 & 4 & 5 & 4 & 3 & 2 & 3 & 2 & 3 & 2 \\
\hline 1010 & 4 & 3 & 2 & 1 & 2 & 3 & 2 & 1 & O & & ? & 3 & 4 & 3 & 2 & 3 & 4 & 5 & 4 & 3 & 2 & 1 & 2 & 3 \\
\hline 1010 & 5 & 4 & 3 & 2 & 3 & 4 & 3 & 2 & 1 & 0 & 1 & 2 & 3 & 2 & 1 & 2 & 3 & 4 & 3 & 2 & 1 & 2 & 3 & 4 \\
\hline 11011 & 4 & 5 & 4 & 3 & 2 & 3 & 2 & 3 & 2 & 1 & 0 & 1 & 2 & 3 & 2 & 3 & 2 & 3 & 2 & 3 & 2 & 3 & 2 & 3 \\
\hline 1001 & 3 & 4 & 5 & 4 & 3 & 2 & 1 & 2 & & & 1 & 0 & 1 & 2 & 3 & 4 & 3 & 2 & 1 & 2 & 3 & & 3 & 2 \\
\hline 11101 & 2 & 3 & 4 & 3 & 2 & 1 & 2 & 3 & 4 & 3 & 2 & 1 & 0 & 1 & 2 & 3 & 2 & 1 & 2 & 3 & 4 & 5 & 4 & 3 \\
\hline 11100 & 3 & 2 & 3 & 2 & 3 & 2 & 3 & 2 & 3 & 2 & 3 & 2 & 1 & 0 & 1 & 2 & 3 & 2 & 3 & 2 & 3 & 4 & 5 & 4 \\
\hline 1110 & 4 & 3 & 2 & 1 & 2 & 3 & 4 & 3 & 2 & 1 & 2 & 3 & 2 & 1 & 0 & 1 & 2 & 3 & 4 & 3 & 2 & 3 & 4 & 3 \\
\hline 0110 & 3 & 2 & 1 & 2 & 3 & 4 & 5 & 4 & 3 & 2 & 3 & 4 & 3 & 2 & 1 & 0 & 1 & 2 & 3 & 2 & 1 & 2 & 3 & 4 \\
\hline 10111 & 2 & 3 & 2 & 3 & 2 & 3 & 4 & 5 & 4 & 3 & 2 & 3 & 2 & 3 & 2 & 1 & 0 & 1 & 2 & 3 & 2 & 3 & 2 & 3 \\
\hline 10101 & 1 & 2 & 3 & 4 & 3 & 2 & 3 & 4 & 5 & 4 & 3 & 2 & 1 & 2 & 3 & 2 & 1 & 0 & 1 & 2 & 3 & 4 & 3 & 2 \\
\hline .0001 & 2 & 3 & 4 & 5 & 4 & 3 & 2 & 3 & 4 & & 2 & 1 & 2 & 3 & 4 & 3 & 2 & 1 & 0 & 1 & 2 & 3 & 2 & 1 \\
\hline 10000 & 3 & 2 & 3 & 4 & 5 & 4 & 3 & 2 & 3 & 2 & 3 & 2 & 3 & 2 & 3 & 2 & 3 & 2 & 1 & 0 & 1 & 2 & 3 & 2 \\
\hline 10010 & 4 & 3 & 2 & 3 & 4 & 5 & 4 & 3 & 2 & 1 & 2 & 3 & 4 & 3 & 2 & 1 & 2 & 3 & 2 & 1 & 0 & 1 & 2 & 3 \\
\hline 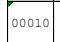 & 3 & 2 & 1 & 2 & 3 & 4 & 3 & 2 & 1 & 2 & 3 & 4 & 5 & 4 & 3 & 2 & 3 & 4 & 3 & 2 & 1 & 0 & 1 & 2 \\
\hline 00011 & 2 & 3 & 2 & 3 & 2 & 3 & 2 & 3 & 2 & 3 & 2 & 3 & 4 & 5 & 4 & 3 & 2 & 3 & 2 & 3 & 2 & 1 & 0 & 1 \\
\hline 2001 & 1 & 2 & 3 & 4 & 3 & 2 & 1 & 2 & 3 & 4 & 3 & 2 & 3 & 4 & 5 & 4 & 3 & 2 & 1 & 2 & 3 & 2 & 1 & 0 \\
\hline
\end{tabular}

Fig. 16. The distances of bold binary values to other values 


\subsection{The Bold Binary Values}

The bold binary values in the sequence is used as the values of clusters. In an artificial intelligence approach, an intelligent system must first be trained so, that it will memorize patterns. Having such memory makes the system be capable of for instance recognizing previously trained patterns. The memorized values of those for-training patterns will be clustered into those bold values. In this research, it will be investigated, how many clusters are the best configuration that will achieve the most accurate results. Now, whenever a pattern needs to be recognized by the mHGN, all the values bold or not will be recognized as bold values. For instance, if the value taken from particular sensor is 10001 (index 19), the mHGN will recognize it as 10000 (index 20). The reason to this is because the smallest Hamming Distance of the value 10001 happens to be between this value and the value 10000, which is 1 . Similarly, if the value taken from particular sensor is 10010 (index 21), the mHGN will recognize it as 10000 (index 20) as well. The reason to this is because the smallest Hamming Distance of the value 10010 happens to be between this value and the value 10000, which is 1 .

Someone might raise a question, whether there is a chance that the Hamming Distance 1 of the values 10001 and 10010 is not only compared to the bold value 10000, but also to one or two other bold values? To answer this question, the following Hamming Distance table shows the answer.

In the above table, it can be seen that in any bold row or in any bold column, the Hamming Distance of 1 is located in two places only. It means that the Hamming Distance of 1 belongs to those on the first adjacent neighbor values.

\section{Conclusion}

From the experiment results it is shown that mHGN has the capability to recognize multidimensional patterns. For simulating a tornado forecast, we have presented results of up to 5D architecture. As already discussed in [15] and [9] there is no modification required if the architecture needs to be extended to bigger sizes of patterns. In the future this capability will be improved to the extent so, that multi oriented of multidimensional patterns will also be recognizable. At this stage it is also observed that mHGN still use a single cycle memorization and recall operation. The scheme still utilizes small response time that is insensitive to the increases in the number of stored patterns.

\section{References}

1. R. T. Cheng and R. E. Smith, "A Nowcast Model for Tides and Tidal Currents in San Francisco Bay, California," in Ocean Community Conference, Baltimore, USA, 1998.

2. J. H. Sorensen, "Hazard Warning Systems: Review of 20 Years of Progress," Natural Hazards Review, pp. 119-125, May 2000.

3. D. B. Kirschbaum, R. Adler, Y. Hong, S. Kumar, C. Peters-Lidard and A. Lerner-Lam, "Advances in landslide nowcasting: evaluation of a global and regional modeling approach," Environment Earth Science, vol. 1, no. 1, pp. 1-14, 2011. 
4. S. Bellaire and B. Jamieson, "Nowcast with A Forecast - Snow Cover Simulations on Slopes," Journal of Something, vol. 1, no. 1, pp. 1-7, 2012.

5. P. Li and E. Lai, "Applications of Radar-based Nowcasting Techniques for Mesoscale Weather Forecasting in Hong Kong," Meteorological Applications, vol. 11, no. 1, pp. 253264, 2004.

6. S. S. Roy, V. Lakshmanan, S. R. Bhowmik and S. Thampi, "Doppler Radar based Nowcasting of Cyclone Ogni," Journal of Earth System Science, vol. 119, no. 2, pp. 183-199, 2009.

7. Y. SuzukiI, Y. Michihiro and M. Honma, "Development of Strong Wind Nowcasting System," in International Symposium on Extreme Weather and Cities, Tokyo, Japan, 2013.

8. B. B. Nasution, R. W. Sembiring, B. V. Sundawa, Gunawan, A. Amelia, Ismael, H. Sunjaya, S. Alifuddin, M. Pardede, Junaidi, M. Syahruddin and Z. Lubis, "Forecasting Natural Disasters of Tornados using mHGN," in IFIP Advances in Information and Communication Technology, Berlin, Springer, 2017.

9. B. B. Nasution, "Towards Real Time Multidimensional Hierarchical Graph Neuron (mHGN)," in The 2nd International Conference on Computer and Information Sciences 2014 (ICCOINS 2014), Kuala Lumpur, Malaysia, 2014.

10. T. Winterrath and W. Rosenow, "The Radar- based Precipitation Nowcasting System RADVOR of Deutscher Wetterdienst for the support of meteorological and hydrological alert systems," in 8th European Conference on Radar in Meteorology and Hydrology, Germany, 2014.

11. Y. Kryvasheyeu, H. Chen, N. Obradovich, E. Moro, P. V. Hentenryck and J. Fowler, "Nowcasting Disaster Damage," arXiv preprint arXiv:1504.06827, 2015

12. J. Ogasawara, K. Tanimoto, O. Imaichi and M. Yoshimoto, "Disaster Prevention and Response Support Solutions," Hitachi Review, vol. 63, no. 1, pp. 236-243, 2014.

13. D. J. Doong, L. Z. H. Chuang, L. C. Wu, Y. M. Fan, C. C. Kao and a. J. H. Wang, "Development of An Operational Coastal Flooding Early Warning System," Natural Hazards and Earth System Sciences, vol. 12, no. 1, p. 379-390, 2012.

14. B. B. Nasution, R. W. Sembiring, B. V. Sundawa, Gunawan, A. Amelia, Ismael, H. Sunjaya, S. Alifuddin, M. Pardede, Junaidi, M. Syahruddin and Z. Lubis, "Realtime Weather Forecasting using Multidimenssional Hierarchical Graph Neuron (mHGN)," in The 16th International Conference on Neural Networks (NN '15), Rome, Italy, 2015.

15. B. B. Nasution and A. I. Khan, "A Hierarchical Graph Neuron Scheme for Real-time Pattern Recognition," IEEE Transactions on Neural Networks, pp. 212-229, 2008. 